\section{MEETINGS AND COURSES}

\section{Annual Courses}

Title: Warwick Medical School Courses on Sexual and Reproductive Health. Venue: University of Warwick, Warwick, UK. Details: See display advertisement on inside back cover.

\section{Throughout 2004/2005}

Title: Courses on Current Issues in Sexual and Reproductive Health organised by The Margaret Pyke Memorial Trust. Venue: London, UK. Details: See display advertisement on page 284 .

\section{Throughout 2004/2005}

Title: Scottish Family Planning Medical Society One-Day Educational Meetings on Family Planning and Reproductive Health Care Topics. Details: See display advertisement on page 283 .

\section{Throughout 2004/2005}

Title: Primary Care Training Centre Courses on Sexual Health and Contraception and Women's Health Management. Details: See display advertisement on page 284

\section{Training Courses}

Title: Centre for Health Planning and Management Postgraduate Courses and Intensive Workshops on International Health and Population Management Skills. Venue: Keele University, Keele, UK. Details: See display advertisement on page 283 .

\section{October 2004}

Title: Fitting Intrauterine Devices Theoretical Training Day for Nurses. Venue RCOG, London, UK. Details: Participants will need to fulfil specific eligibility criteria. Limited places available. Information: Alison Orr. Tel: +44 (0) 207436 8379. Fax: +44 (0) 207580 2495. E-mail: mpmtrust@hotmail.com.

\section{5-19 November 2004}

Title: The Menopause and Beyond, Venue: University of Warwick, Warwick, UK. Details This 5-day non-residential course open to doctors, nurses and other health professionals is a stand-alone course though it may also form the basis for a Postgraduate Award (Masters level 25 CATS points) or may be taken as part of the full MSc course. It provides a total update on the menopause and its practical management including a critical review of the evidence base for HRT. Information: Guillermina AnorveGalicia, Division of Clinical Sciences, Warwick Medical School, Westwood Campus, University of Warwick, Coventry CV4 7AL, UK. Tel: +44 (0) 247652 2913. Fax: +44 (0) 247652 4311. Email: G.Anorve-Galicia@warwick.ac.uk.

\section{November 2004}

Title: Current Thinking in Women's Bleeding Disorders and Haemostasis. Venue: RCOG, London, UK. Details: Topics to be covered include: an introduction to women's bleeding disorders, who has them and how to identify a bleeding disorder; thrombotic disorders; issues surrounding contraception and pregnancy; preconceptual planning; decision making in menorrhagia in primary care and risk management. Cost: 550.00 . Accreditation: CPD points applied for. Information: Anna, The Haemophilia Society. Tel: +4 (0) 2073919136. E-mail: anna@haemophilia.org.uk.
25-26 November 2004

Title: Current Choices Conference. Venue: RCOG, London, UK. Details: See display advertisement on page 280 .

3 December 2004

Title: Impact of STIs and HIV on Women's Reproductive Health (Joint RCOG/BASHH Meeting). Venue: RCOG, London, UK. Details: This meeting will provide an update on the recent evidence of the complications and managemen of STIs and HIV in women's reproductive health. The meeting is aimed at GPs with a special interest in sexual health, consultants, NCCGs and trainees in obstetrics and gynaecology and associated professions. Accreditation: RCOG CPD category E/1 (5 credits). Information: Conference Office, RCOG, 27 Sussex Place, Regent's Park, London NW1 4RG, UK. Tel: +44 (0) 207772 6245. Fax: +44 (0) 207772 6388. Email: conference@rcog.org.uk.

\section{6-10 December 2004}

Title: Osteoporosis: A Practical Approach to Diagnosis and Clinical Management. Venue: University of Warwick, Warwick, UK Details: This 5-day non-residential course open to doctors, nurses and other health professionals is a stand-alone course though it may also form the basis for a Postgraduate Award (Masters level 25 CATS points) or may be taken as part of the full MSc course. Information: Mandie Drew, Division of Clinical Sciences, Warwick Medical School, Westwood Campus, University of Warwick, Coventry CV4 7AL, UK. Tel: +44 (0) 247657 4514. Fax: +44 (0) 247652 4311. Email: Mandie.Drew@warwick.ac.uk.

18-21 January 2005

Title: DFFP Course. Venue: Education Centre, Chesterfield Royal Hospital NHS Trust, Chesterfield, UK. Details: Modules 5 and 6 will be on 18 and 19 January and will take the form of a STIF course with priority given to delegates attending the full DFFP course. Modules 2 and 3 will be on 20 January and Module 4 will be on 21 January. Limited places available. Accreditation: DFFP (Section 63) Information: Jean Hassell, Education Centre, Chesterfield Royal Hospital NHS Trust, Chesterfield S44 5BL, UK. Tel: +44 (0) 1246 512057. Fax: +44 (0) 1246 512685. Email: jean.hassell@chesterfieldroyal.nhs.uk.

18, 19 and 25 January 2005

Title: DFFP Basic Theory Course with STI Day. Venue: Chancellor's Conference Centre, Manchester, UK. Details: See display advert on page 282 .

\section{4-26 January 2005}

Title: The Sexual \& Reproductive Health Training Partnership Residential Course for Potential Instructing Doctors. Venue: London, UK. Details: See display advertisement on page 283.

\section{7-19 February 2005}

Title: Potential Instructing Doctors Course. Venue: The Cottons, Knutsford, UK. Details: See display advert on page 282 .

\section{March 2005}

Title: MFFP Part 2 Preparation Course. Venue: Liverpool Women's Hospital NHS Trust, Liverpool, UK. Information: Mrs Carmel M Farrell, Liverpool Women's Hospital NHS Trust, Mersey Region Group for Family Planning Training, 2nd Floor, Crown Street, Liverpool L8 7SS, UK. Tel: +44 (0) 151702 4102. E-mail: Carmel.Farrell@1wh-tr.nwest.nhs.uk.
11-13 April 2005, 27-29 June 2005 and throughout 2005

Title: FFPRHC Diploma in Family Planning and Reproductive Health Care Theoretical Courses. Venue: Liverpool Women's Hospital NHS Trust, Liverpool. UK. Details: A 2.5-day Faculty-approved theory course covering all six modules. Information Mrs Carmel M Farrell, Liverpool Women's Hospital NHS Trust, Mersey Region Group for Family Planning Training, 2nd Floor, Crown Street, Liverpool L8 7SS, UK. Tel: +44 (0) 1517024102. E-mail: Carmel. Farrell@1wh-tr.nwest.nhs.uk.

\section{3-14 April 2005}

Title: STIF Course. Venue: Chancellor's Conference Centre, Manchester, UK, Details: The aim of the course is to equip participants with the basic knowledge, skills and attitudes of the effective management of STIs outside the GUM setting. Accreditation: FFP, RCN and BASHH. Information: Irene Healey, 63-65 Palatine Road, Withington, Manchester M20 3LJ, UK. Tel: +44 (0) 161434 8629. Fax: +44 (0) 161448 1889. Email: i.healey@man.ac.uk.

21 April 2005

Title: Annual Doctors and Nurses Family Planning Update Day. Venue: Hanover International Hotel, Stretton, Warrington, UK Details: A 1-day updating course covering a variety of interesting topics presented by leading specialists. NB. Book early as places are strictly limited. Accreditation: FFP CME. This conference is also run in association with The Mersey Deanery. Information: Mrs Carmel M Farrell, Liverpool Women's Hospital NHS Trust, Mersey Region Group for Family Planning Training, 2nd Floor, Crown Street, Liverpool L8 7SS, UK. Tel: +44 (0) 151702 4102. E-mail: Carmel.Farrell@1wh-tr.nwest.nhs.uk.

14-15 September 2005

Title: STIF Course. Venue: Chancellor's Conference Centre, Manchester, UK. Details: The aim of the course is to equip participants with the basic knowledge, skills and attitudes of the effective management of STIs outside the GUM setting. Accreditation: FFP, RCN and BASHH Information: Irene Healey, 63-65 Palatine Road Withington, Manchester M20 3LJ, UK. Tel: +44 (0) 161434 8629. Fax: +44 (0) 161448 1889. Email: i.healey@man.ac.uk.

\section{2-16 October 2005}

Title: 14th European Academy of Dermatology and Venereology Congress. Venue: The London ExCeL Exhibition Centre, London, UK. Details: The scientific programme will cover all the main topics in dermatology and venereology and will include keynote speeches, symposia, workshops, courses, poster sessions and free lecture communications. There will also be a $10000 \mathrm{~m}^{2}$ pharmaceutical exhibition, posters, catering and general circulation area for delegates Accreditation: CME accredited, recognised by the American Academy of Dermatology. Information: Chris Garrett. Tel: +44 (0) 207391 6358. Fax: +44 (0) 207388 0487. E-mail: eadv@bad.org.uk.www.eadv2005.com.

There is a charge of $£ 50.00+$ VAT for each meeting/course publicised in this section of the Journal. This will guarantee inclusion in the issue requested. For guaranteed inclusion in the January 2005 issue all course details should be with Sarah Monger by 12 November 2004. For a booking form please contact Sarah Monger at PMH Publications, PO Box 100, Chichester, West Sussex PO18 8HD, UK. Tel: +44 (0) 1243 576444. Fax: +44 (0) 1243 567456. E-mail: sarah.monger@pmh.uk.com.

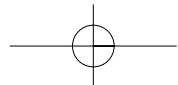

